\title{
Lo Hmano Y Lo Natural En El Existencialismo De Blas de Otero. Búsqueda afanosa. Un Estudio Crítico.
}

\author{
Profesora asociada Hanan Younus Mohammed \\ Universidad de Bagdad -Facultad de Letras \\ Departemento de Inglés. \\ E-mail:hnnbbs@yahoo.com.
}

\section{Resumen:}

La cultura intelectual española, en particular, en el siglo XX, pasó por varias importantes transiciones de acuerdo con las segregaciones de los resultados sociales afectados por la situación política aquel etapa, sobre todo en las décadas medianas del mismo siglo, lo que se refleja directamente en la producción literaria de los ilustres literarios, tanto a nivel de la poesía , el teatro y la novela. En ese aspecto descriptivo, encontramos que el poeta español Blas de Otero ha sido una voz resonante en su su entorno social, con mayor influencia en el oido del receptor español.

El poeta Blas de Otero es uno de los ilustres de la literatura social, quien discutió en sus poesías la mayor parte de los problemas intelectuales que se relacionan con la estructura formativa del ser humano y su relación con su entorno a su alrededor, según la lógica de la existencia humana, agitando una cadena de cuestiones de conciencia que justifican los sufrimientos y los dolor de la sociedad española durante las décadas de los años cuarenta y cincuenta del siglo pasado, por lo tanto, el planteamiento en sus poesías se tarta de unas discusiones de la lógica y analizar sus propósitos, lo que llevó a una clara referencia a la relación del ser humano, la relación del ser humano con su destino decretado. Esta convergencia de la relación viene afirmando el reflejo de Hegl y su influencia en la creatividad poética de Blas de Otero.

En nuestro trabajo de investigación hemos recalcado que la voz de nuestro poeta Otero, es la voz de la búsqueda de la verdad absoluta de las cosas y de la creación, y que constituye la base de la inquietud que vive el mundo confuso ante este conocimiento en un momento en que los rasgos de la violencia, el dolor y el sufrimiento que el verso de Blas de Otero los reflejan con un planteamiento de poética que palpita vida de España y el Hombre Español. 


\section{Introducción:}

\section{A-Prologo:}

El movimiento literario-ideológico español se encuentra afectado por las olas de intelectualidad europea,en los finales del siglo XIX y los principios del siglo $\mathrm{XX}$, pero, normalmente ,los literatos españoles tratan con las tendencias con un tipo de novedad por lo cual, la misma tendencia siempre se inviste otra forma de entendimiento y otro molde de hecho, diferentes de lo usual en el resto de Europa.

El existencialismo tiene unas referencias directas que aparecen los finales del siglo XVII,pero el filósofo danés Sören Kierkegaard (1), le dió la fórmula final y la comprensión limitada, desarrollando en el período de entre guerras.Básicamente, postula que existe una gran diferencia entre ser y existir.Ser es un hecho pasivo ,los objetos "son",porque no protagonizan ninguna acción,en todo caso son receptores de ellas ,no pueden elegir su propia destino.Son lo que son en sí ,sin posiblidad de cambiarse a sí mismo.Sin embargo ,el hombre existe y no tiene por qué coincidir con lo que es ,puede cambiar su propio ser con sus decisiones.

Así pues ,el hombre no sólo existe ,sino que además debe hacerlo .En el existencialismo hay una defensa de la vivencia subjetiva por encima de la objetividad pura ,como repuesta a la filosofia de Hegel(2) que creía en la posibilidad de un conocimiento racional, objetivo y puro de todos las cosas del mundo.

Una corriente importantísima dentro del existencialismo ,y que probablemente marca más que ninguna otra poética oteriana ,es la iniciada por Jean PaulSartre (3), una filosofía primodialmente moral ,que denuncia el compromise del hombre con su propia libertad .No existe una predestinación ,no hay dioses ni almas ,cada uno es responsable de sus propios actos ,está sólo ,sin más .Ese sentimiento de soledad existencial es uno de los pilares de esta etapa poética de Blas de Otero.

Normalmente el existencialismo en la literatura española viene muy afectado por las preocupaciones de la sociedad misma y el lugar que lo ocupa ,asi que, en Blas de Otero el existencialismo aparece en una etapa de transición ,como respuesta de la crisis espirtual de 1945 durante la cual pierde la fe.A través de ello llega a lo que será el estudio definitivo de su 
poética ,la poesía social .Sin embargo ,esta etapa tiene entidad propia y valor de por sí.

En la segunda mitad de la década de los cuarenta del siglo pasado ,figuraba la inclinación de muchos literatos españoles hacia el existencialismo para agitar y mover la sociedad para levantar el nivel del motaje de una españa nueva ,desarollada con una ideologia puramente española.Desde aquí viene la importancia de los elementos existenciales en la poesía de Blas de Otero.

Indicamos que el existencialismo de Otero se concentra en las tres obras epecial,que son: Ancia,Redoble de Conciencia y Angel Firamente Humano .Estas obras son el cubo que contiene el ánimo del existencialismo como una corriente peculiar en la poesía española ,donde viene usados fundamentos del amor y muerte, vida y lucha,deprisión y capricho y muchos otros más que globalizan un sentido iluminante del existencialismo español.

\section{B-Su Vida y Obra:}

Es uno de los mejores poetas del siglo XX, nació en Bilbao en 1916 y murió en Madrid en 1979.Estudió derecho ,carrera que no ejerció.Tras dedicarse a la enseñanza por algúno tiempo ,se consagra por entero a la poesía (4). Terminó sus estudios en Zaragoza en 1935 ,y cuando empezó la guerra en la ruina ,regreso a la ciudad natal Bilbao con su familia . Cuando tenía 7 años entro en un colegio de jesuitas ,Su casa era para él refugio y remanso de paz, un microuniverso mitificado de tranquilidad y juegos, habitado por él mismo, sus padres, su hermano y su institutriz, mademoiselle Isabel. Por el contrario, el colegio representaba una suerte de infierno represor para el niño. En el año 1941 trabajó como asesor jurídico a la vez que veía crecer su prestigio como escritor. En 1943, incapaz de soportar el conflicto con su vocación, volvió a Madrid para matricularse en Filosofía y Letras, con el plan de emular a otros poetasprofesores y ganar cátedra de Literatura.

Hay muchas acciones que influyen en su vida, la muerte de su hermano y su padre ,donde empezó su obesión por la muerte , además de todo eso, en el año 1945 se recluió en el sanatario de Usurbil porque tenía una terrible crisis depresiva .

En su vida relegiosa, Otero trabajó como un miembro de la Federación Vizcaína de Estudiantes Católicos, congregante de Los Luises 
de San Estanislao de Kostka.Incluso firmaba sus poemas en aquel entonces como "Blas de Otero, C.M.": Congregante Mariano. En este periodo inció a publicar su poesía, donde observamos su creencia relegiosa e influenciados por los misticos españoles y la literatura cristiana. En la revista jesuítica de "Los Luises " publicó su obra "Baladitas humildes " . En su ciudad, especialmente con sus amigos formó interesantes grupos artísticos como el primero "Los Luises","Alea" y "Nuestralia" .Podió hacer relaciones con los personajes culturales cuando inció a moverse en los ambientes artísticos.En 1942 fue el primer libro "Cántico espirtiual " en este libro practicamente desconocido de carácter religioso ,con huellas clásicas en sus endecasílabos, villancicos. En la segunda etapa parece el lema " a la inmensa mayoría ", empieza con la obra "Pido la paz y la palabra " en 1955 y "En Castellano " en 1959 ,su nueva ideología marxista le llevará a solidarizarse con los marginados, con la colectividad,y los que sufren en esta tierra triste y abatida bajo la dictadura, $\mathrm{y}$ a buscar ante todo la paz y la libertad. España y sus personajes tienen gran papel en su poesía , donde pasarán a ser los protagonistas y destinatarios de sus versos .En las obras que parecen en 1963 y 1964 ,lleva en intenso fondo histórico y social . Cuando sufrió de la crisis ,se destruyó uno de sus poemas de la amistad, su firme posición religiosa y su cándida valoración poética. Sin embargo,la mejor terapia fue en la creación poética y artistica.En los años (1950-1951) escribió las primeras obras importantes : Ángel fieramente humano, Redoble de conciencia y Ancia (5), aquella que busca desesperadamente amarras existenciales y esenciales, hablando de sus problemas personales ,amorosos ,vitales ,y de sus dudas religiosas.

En 1955 ya fue considerado uno de los grandes poetas de la posguerra . En sus obras poéticas aparece su evolución que se ha definido con estas palabras : del yo al nosotros, entonces, por su trayctoria poetica, Otero resume la evolucion de la poesia española de su tiempo.Los temas de el anhelo de paz, las ansias de libertad y de un futuro mejor. Junto a una actitud crítica ,aparece la llamada a la esperanza .El poeta, libre ya de angustias ,quiere que su voz sea decididamente positiva, concibe ahora la poesía como lucha constructiva. El poeta trato por su estilo revela preocupaciones de renovación formal :introduce ritmos nuevos, imagenes insolitas, audaces asociaciones de frases, incluso toques surrealistas (6),sus obras se dividen en : 


\section{Libros de poesía}

- Cuatro poemas, Editor J. Díaz Jácome, 1941.

- Cántico espiritual, Cuadernos del Grupo Alea, San Sebastián, 1942.

- Ángel fieramente humano, Ínsula, Madrid, 1950.

- Redoble de conciencia, Instituto de Estudios Hispánicos, Barcelona, 1951.

- Pido la paz y la palabra, Ediciones Cantalapiedra, Torrelavega (Santander), 1955.

- Ancia, Editor Alberto Puig, Barcelona, 1958 [prólogo de Dámaso Alonso].

- Parler clair / En castellano, Pierre Seghers, París, 1959 [edición bilingüe de Claude Couffon].

- En castellano, Universidad Nacional Autónoma de México, México, 1960.

- Ángel fieramente humano y Redoble de conciencia, Losada, Buenos Aires, 1960.

- Que trata de España, Editorial R.M., 1964 [edición castigada].

- Que trata de España, Ruedo Ibérico, París, 1964.

- Historias fingidas y verdaderas, Alfaguara, Madrid, 1970.

- Pido la paz y la palabra, Lumen, Barcelona, 1975 [introducción de José Batlló, primera edición completa en España].

- En castellano, Lumen, Barcelona, 1977 [primera edición en España].

- Que trata de España, Visor, Madrid, 1977 [primera edición completa en España].

- Hojas de Madrid con La galerna, Galaxia Gutenberg-Círculo de Lectores, Barcelona, 2010 [edición de Sabina de la Cruz, prólogo de Mario Hernández].

\section{Recopilaciones}

- Con la inmensa mayoría, Losada, Buenos Aires, 1960 [con Pido la paz y la palabra y En castellano].

- Hacia la inmensa mayoría, Losada, Buenos Aires, 1962 [con Ángel fieramente humano, Redoble de conciencia, Pido la paz y la palabra y En castellano].

- Que trata de España, Editora Nacional de Cuba, La Habana, 1964 [con Pido la paz y la palabra, En castellano y Que trata de España]. 


\section{Antologías}

- Antología (y notas), Mensajes de Poesía, Vigo, 1952.

- Esto no es un libro, Universidad de Puerto Rico, Río Piedras, 1963.

- Expresión y reunión (1941-1969), Alfaguara, Madrid, 1969.Reedición (1981)

- Mientras, Javalambre, Zaragoza, 1970.

- País (1955-1970), Plaza y Janés, Barcelona, 1971 [prólogo de José Luis Cano].

- Verso y prosa, Cátedra, Madrid, 1974 [edición del autor].

- Todos mis sonetos, Turner, Madrid, 1977 [prólogo de Sabina de la Cruz].

- Poesía con nombres, Alianza, Madrid, 1977.

- Antología poética, Bibliotex, Bilbao, 2002 [introducción de Pablo González de Langarika] (7)

\section{II-Hombre y Tierra en el existencialismo de Blas de Otero.}

Para enfocar la luz en el tema del existencialismo que la literatura española cobria en los cuarenta del siglo XX,tenemos que destacar la labor poética que ejercian los promovedores de las generaciones consecutivas que formaban la de la poesía social y la de la revista Escorial.Dentro de este desarrollo ideológico y cultural se emana Blas de Otero como un grito muy influyente en los medios literarios que ha podido dar un rumbo nuevo del concepto existencial español,a pese que en la litertura ,el compromiso de conciencia del existencialista exige que éste plante en cada obra del problema filosófico o moral.Generalmente se trata del desarrollo de una "situación límite "que conduce al absurdo y a la salida del acto gretuito -una gratuidad de Fuertes reminiscencias surrealistas y un absurdo con el que conduce tará todo un futuro movimiento , un absurdo interior ,causa ,no consecuencia,de la incomunicabilidad social (8).

Además de muchos elementos que usaba el poeta nuestro ,el existencialismo para él es un uso para designar a una corriente filosófica o de pensamiento considerada el positivismo como de corte irracionalista,que tuvo su origen en el siglo XIX y se prolongó más o menos hasta segunda mitad del siglo XX.La existencia precede a la esencia, es el fase fundamental en Otero y sus tratos ante el ser humano,es decir,para él no hay una naturaleza humana que determine a los individuos, sino que sus actos los determinan quiénes son,así como el significado de sus vidas. 


\section{1-La Preocupación Humana:}

La preocupación humana por destino desconocido de los seres es un promoter principal con que la poesia de Otero se mueve y se dirige hacia presenter unos resquicios de la meditación intelectual para salvar el ser humano de sus sufrimientos y congojas. El verso de Blas de Otero afirma el existencialismo defiende que el individuo es libre y totalmente responsable de sus actos.El verso nuestro incita en el ser humano la creación de una ética de la responsabilidad individual , aportada de cualquier sistema de creencias exteno a él.Para el verso de Otero ,hay una búsqueda de una ética que supere a las moralinas y prejuicios.Tanto que en respecto a los otros, esta lucha del hombre por encontrar su propia salvación no tiene fin sino en el hombre mismo.Por eso ,el poeta corta el nudo gordiano de la cuestión alterando los terminus de su problemática.Ya no es Dios quien le importa, sino los hombres que desasosgadamente viven y mueren sin encontrar la paz para sus almas ni la felicidad para sus cuerpos(9), igual que notamos en lo siguientes en su poema :

\section{Pido la paz y la palabra}

\section{A la inmensa mayoría}

Aquí tenéis ,en canto y alma, al hombre aquel que amó ,vivió, murió por dentro y un bueno día bajó a la calle :entonces comprendió :y rompió todos sus versos.

Así es,así fue.Salió una noche echando espuma por los ojos ,ebrio de amor ,huyendo sin saber adónde: a donde el aire no apestase a muerto.

Tiendas de paz, brizados pabellones, eran sus brazos ,como llama al viento:

olas de sangre contra el pecho, enormes olas de oido, ved por todo el cuerpo (10.) 
En estos versos vemos la preocupación directa de Otero por el sentimiento de los otros, viviendo una situación congajosa por el destino del hombre,por lo cual notamos que Blas de Otero no va mucho más lejos de los planteamientos de los postulados del existencialismo como Soreno Kierkegoard y Frieddrich Nietzsche(11) y Fiodor Dostoyevski(12), pero sus medidas y elementos españles puramente según él veía de las aportaciones sociales, ya que en la poesía estudiada viene cristalizada la violencia interhumana y sus formas, encontrándolos tratados como soluciones y contestos ante preguntas para arreglar el estado de la humanidad y colocar el desperso social, tal como descubre estos versos en este poema :

\section{Entonces y ademas}

Cuando el llanto ,partido en dos mitades, cuelga, sombriamente, de las manos, y el viento ,vengador, viene y va, estira del corazón,ensancha el desamparo.

Cuando el llanto ,tiendo como llanto silencioso , se arrastra por las calles solitarias, se enreda entre los pies, y luego suavamente se deshace.

cuando morir es ir donde no hay nadie, nadie ,nadie ,caer , no llegar nunca, nunca, nunca :morirse y no poder hablar, gritar, hacer la gran pregunta(13).

Paralelamente el poeta en los versos antes citados sensibiliza las entrañas del ser humano, por lo tanto ,la comlejidad que sufria la sociedad españa ve una salida adecuada en el verso de Otero porque la presencia del ser humano en su poesía forma un elemento muy efectivo y vital, llevando una caraterización propia y peculiar para indicar a la eficacia del individiuo español como el bueno ejemplo de reflejo de la voluntad humana ,de modo que Blas de Otero se convierte así en el origen y destino de su propio canto.No le lleva a esa actitud una postura de egocentrismo lírico, sino todo lo contrario. Su actitud pretende unir a todos los hombres para los que escribe en uno solo. El círculo que se abre entre el creador y la criatura para la que se canta, se cierra en el propio poeta (14). 
Los elementos encontrados en la poesía de Blas de Otero afirman que el poeta siempre entiende que el existencialismo es como una reacción frente a las tradiciones filosóficos imperantes,tales como el racionalismo o el empirismo que buscan descubrir un orden legitimo dentro de la estructura del mundo observable, en donde se pueda obtener el significado universal de las cosas, que indican una necesidad muy importante que la sociedad española carece después de unas fases de sufrimiento y concoja.La poesía de Blas de Otero no va lejos de el planteamiento de Sartre ,Camus y Beauvoir que dan a conocer una ficción que popularización temas existenciales del tipo de la libertad ,la noda ,el absurdo ,entre otros .El verso estudiado por nosotros a firma el rechazo a pertenecer a cualquier escuela de pensamiento ,el repudiar la adecuación a cualquier cuerpo de creencias , y especialmente de sistemas y una marcada insatisfacción hacia la filosófia tradicional ,es decir ,nostros tocamos ,y sentimos una lectura directa y precisa del sufrimiento de una sociedad puramente española, con una convocotoria de rebeldia interna del sí mismo. Pero el poeta frente al espejo esencial de la página en blanco,consentirá en plasmar los fragmentos de su rupture,recuperando aquello de más breve duración .De este modo los instantes se harín la pura evidencia del tiempo,la alegría innúmera de las horas.Y antes de ceder al abismo que conduce a la desustancialización del ser-hastío que subrayar la renuncia-,la palabra captará lo fugaz como celebración de un espejo propio que conforma toda ausencia de temporalidad (15),los siguientes versos lo expresan:

\section{Angel fieramente humano}

\section{La tierra}

Un mundo como un árbol desgajado. una generacion desarraigada. unos hombres sin más destino que apuntalar las ruinas. rompe el mar

en el mar ,como un hymen inmenso, mecen los árboles el silencio verde, las estrellas crepitan yo las oigo 
sólo el hombre está solo. Es que se sabe vivo y mortal.

es que se siente huir-ese río del tiempo hacia la muerte-.

es que quiere quedar. Seguir sigiendo, subir, a contramuerte, hasta lo eterno.

le da miedo mirar .cierra los ojos

para dormer el sueño de los vivos.

Pero la muerte, desde dentro,ve.

pero la muerte, desde dentro, vela.

pero la muerte, desde dentro, mata.

el mar-la mar -,como un hymen inmenso,

los árboles moviendo el verde aire,

la nieve en llamas de la luz en vilo (16).

Las penas aquí forman una resperación continua en los versos de nuestro poeta hacienda una relación fija entre el hombre y la tierra iendose hacía el sentido de la muerte ya que el factor existencial en Otero se le ha atribuido un carácter vivencial ,ligado a los dilemos ,astragos , contradicciones y alusión directa a la estupidez humana que viene reflejada en su poesía para subrayar una corriente filosófica que discute y propone soluciones a los problemas más propiamente inherentes a la condición humana , como el absurdo de vivir, la significancia y insignificancia del ser ,el dilema en la guerra ,el eterno tema del tiempo ,la libertad ,la relación dios-hombre, la naturaleza del hombre, la vida y la muerte .Un toda que late en los versos de Otero encontrando hueco de respirar el tratamiento social humano que en muchos puestos de su poesía nos coincidimos para levanter el fundamento del existencialismo de Otero. Pero amenudo se apartaba de este propósito por una imaginación creative irreprimiblemente original y un elaborado gusto por la metáfora que hacen de él,como no lo consiguen sus visions politicos y sociales ,uno de los poetas más vigorosos y atrctivos de la España contemporáneo (17), como aquí figura en este poema :

\section{Colorolor}

Otoño de cobre

frondas de la Moncloa

pájaro Amarillo

de Olmedo

cadena destrozada

del Tajo

octubre vacilante 
en las márgenes del Ebro

miranda huele a pan

alicante a Puerto

Madrid a cielo azul

Zamora a plaza pura otoño

de España

uncido

como un buey rojo a mi palabra (18).

\section{2-La Trascendencia existencial del lugar:}

Los fenómenos geográficos siempre están hallados en el ánimo creative de la producción existencial del verso Oteriano, de modo que la lectura sensible de la poética de Otero considera una revision del lugar español y una puntuación del factor natural de los seres y enseres.

La geografia en los versos señala una labor extencial muy clara en Blasé de Otero,porque el afán en reflejar la preocupación patriotica para hacer un enlace entre el hombre y su tierra de modo que el existencialismo en Otero busca revelar lo que rodea al hombre con su entorno social ,hacienda una descripción minuciosa del medio material y abstracto en el que se desenvuelve el individuo ,para que éste obtenga una comprensión propia y pueda dar sentido o encontrar una justificación a su existencia.Por lo tanto la existencia en Blas de Otero no forma un enfrentamiento con Dios sino una evocacio interrogativa por los motivos de las esencias y las necesidad es del ser humano como ecos de un incendio ideológico para cominar hacia el desarrollo elemental que conduce por fin un capricho hacia el progreso explosivo sirviendo la misión humanistica social. La mezcla de lo existencial con lo social así como el juego de palabras que lo toma de Blas de Otero .Todo ello configure una de las voces más singulars del panorama poético de los últimos quince años (19).

La poesía de Otero busca dibujar una verdad y realidad otra que los otros querían ,es decir , la palabra que forma el verso oteriano combina un espacio donde nada el individuo desde nacer hasta morir ,por lo cual podemos encontrarnos ante un paisaje extensor de geografia española.Esta idea que está detrás es que uno puede escger su propio camino a demás de normas o criterios universals u objetivos, aunque se haya llamado a esta posición el individualismo moral. Apesar del caracter profundamente intropectivo de su queja,nunca pierde de vista el hecho de que su intención es comunicarla a los demás . Como es lógico ,poemas que tartan de ahondar en la sensación de ser un cadaver deshecho y ambulante en un 
mundo repugnante destrozado y hostil ,no son fáciles de lectura(20),tal como descubren estos versos:

\section{¿Termina?Nace}

Puedo ser que estamos ya al cabo de la calle.

Que esto precisamente fuse el fin

O el cabo de la calle.

Puedo suceder que aquí precisamente

Se acbe el cabo

$$
\text { de la calle. }
$$

Puedo ser que estemos ahora llegando, que hayamos estado aquí antes, y todo puedo ser, y puedo ser que no sea esta calle.

Nadie.

¿Es que no hay nadie, es que aquí no ha quedado alguien?

Puede ser que esto sea una sombra, eso unos árboles(21).

El sentido del mensaje ,que el verso de Otero lleva,afirma siempre un acercamiento entre la verdad y la experiencia que se encuentran ligada a demás de las contemplaciones imparciales como una idea firmante en la justificación de la existencia humana añadiendo la creencias y la preporación moral del individuo ,por que la expeniencia personal y actuar de acuerdo con convicciones propias es esencial para llegar a la verdad , aunque en las creencias existan una afirmaciones que recaen fuera de la voluntad humana ,pero la importancia del existencialismo en el verso de Otero viene enfatizando la acción individual al decidir sobre asunto de moralidad y de verdad.Blas de Otero y através de sus poesía quiere definir la existencia del ser humano como una realidad que obedece a la influencias externas, no porque niegue el papel del pensamiento racional ,sino porque cree que las cosas más importantes de la vida no son accesibles a la razón o a la ciencia ,por lo cual la relación entre ser y el tiempo por una parte y la existencia de un entorno material y moral al que hay que obedecer. Si tuviéramos que determiner el tema fundalmental en que se inspira el libro, diríamos que es la caridad hacia los que sufren.De cada de estos seres el poeta recoge su más hondo canto,su frustración más profunda:El dolor de los enfermos, la soledad de los Los locos ,la consumición carnal de Los leprosos , la sombra que rodea el mundo de los 
ciegos, la tristeza de los olvidados (22), como bien lo vimos en estos versos:

\section{Cantil}

ahora canto mis manos

manos de muerto vivas.

mudas manos de muerto

moviéndose todavía.

maravillosos dedos

palmas de oro antiguas,

duros dorsos de estatua,

manos de nadie ,mías.

Ahora miro mis manos .

extreno de mi agonía.

manos de muerto

moviéndose.

mudas orillas.

Cantil cortado a pico.

límite que me termina

de matar .Aspas rotos,

en carne viva (23).

Los matices naturales viene usados como indicadores de un concepto existencial reflejando un sentimiento muy profundo de hollar un ámbito adecuado para que el Hombre pueda realizar grandes éxitos atraves de sus caprichos.

En verdad ,allí se plantea que el objetivo de la obra estudiada de Otero es la búsqueda del sentido del ser humano.El silencio generado en el verso de Otero es una referencia o un asombro ante la existencia humana que se encuentra llena de concojas y sufrimiento de los sucesos que recaen fuera de la voluntad y el capricho esperado ensimismado del individuo en general y el hombre español en especial, referiendo a la realidad severa y fuertemente acechada por muchas lí mitaciones impuestas por otros así que la coractistica principal del existencialismo en Otero es la atención que presta a la existencia concreta ,individual y única del hombre ,sin que rechace la especulación abstracta y universal. Tampaco es dificil compenetrarse con su intuición acerca de cómo un estado de caducidad o 
muerte -el invierto ,el crepentrable al paso del tiempo ,y por lo tanto más cosolador que una situacion de nacimiento o comienzo vital (24), este poema indica bien a lo anterior:

\section{Hijos e la tierra}

Parece como si el mundo caminase de espalda hacia la noche enorme de los acantilados.

Que un hombre , a hombros del medio,trepase por las faldas

hirsutas de la muerte, con los ojos cerrados.

Europa,amontonada sobre España, en escombros:

sin norte ,Norteamérica, cayéndose hacia arriba:

recién nacida, Rusia, sangrándole los hombres:

Oriente ,dando tumbos :y el resto , a la deriva.

Parece como si el mundo me mirase a los ojos, que quisiera decirme no sé qué, de rodillas:

alza al cielo las manos, me da a oler sus manojos

de muertos, entre gritos y un trepidar de astillas.

El mar,puesto de pie,

le pega en la garganta con un látigo verde:

le descantilla:de

repente, echando espuma por la boca, le muerde(25).

Sin embargo ,los elementos de tierra ,naturaleza,seres y otras cosas son el tema central de su reflexión ante la existencia del ser humano ,en término, varios y diversos de no estar fuera de su mundo en que vive.

El sufrimiento del hombre en la poesía de Blas de Otero proviene de la angustia que él mismo se encuentra arrojada a ella según la existencia impuesta por la voluntad sin que el ser humano tenga una intervención afectiva, al mismo tiempo podemos ver que la angustia de un alma consciente de encontrarse condenda a ser libre, significa tener en cada instante de la vida y la perespectiva optimista, que le lleva a superar cualquier oposición entre el hombre y Dios.Puede verse como una denuncia de la alienación, que pesa sobre el individuo,sobre la familia y, sin duda, de manera general, sobre el conjunto de la sociedad española (26). 
El verso de Otero subraya el existencialismo como una reflexión verdadera de la realidad social y las preocupaciones de una sociedad con sus componentes y elementos,ya que esa reflexión contempla lo misterios y proporaciona una especie de verdad filosófica ,moral y religiosa que no puede ser verificada mediante procedimientos científicos, pero que es confirmada mientras ilumina la vida de cada uno ,esta visión poética existencial viene cristalizada a través de una combinaciones temáticos que tocan el hondo sufrimiento humano.

\section{La Conclusión:}

La investigación en el existencialismo de Blas de Otero es una labor muy compleja y dura por que el poeta nuestro es un maestro que globaliza su poesía unos instrumentos sería difícil de separar, ya que su visión generalizada es el factor humanístico,por que la poesía de Otero se convierte en lo que pretende ser raíces del ser individual y colectivo ,fuente de comincación concreta para una comunidad que actúa.

La voz de Blas de Otero es una convocatoria para explorar un mundo de la angustia ,donde Dios y la mujer, por ejemplo ,son los polos de una misma búsqueda de lo absoluto,de la verdad.A base de eso ,el poeta plantea en su poesía ,unas intenciones teóricas que indican a su preocupación por los otros reflejando sus caprichos y sufrimientos.

El Hombre es el objetivo directo de nuestro poeta,que,por él,busca siempre salida para salvarle de un laberinto ideológico preocupante por su fin .De modo que el verso oteriano está dirigido por la búsqueda de misteriosos fundamentos como la muerte, por lo cual lo trata con una lengua de amor y colma para poder hacer un criterio adecuado para continuación de la vida.

El planteamiento existencial en la poesía de Blas de Otero es el más aceptable dentro otros muchos que escribían poesía de su época,por el motivo de que el asunto utilizado para exaltar este caso no representa un enfrentamiento con Dios,sino es una búsqueda permanente por la finalidad de los seres y enseres,a través de unos eslabones teóricos del existencialismo en esta vez español puramente. 


\section{IV-Las Notas:}

1-Sören Kierkegaard: nació el 5 de mayo de 1813 en Copenhague (Dinamarca). Hijo de un rico comerciante y estricto luterano. Cursó estudios de teología y filosofía en la Universidad de Copenhague. En la universidad abandona el protestantismo luterano para entregarse a una extravagante vida social. Cuando muere su padre en 1838, reemprende sus estudios teológicos. Dos años después se prometió con Regine Olson, aunque su incapacidad para aceptar el vínculo hizo que rompieran. Tras escribirla vibrantes cartas de amor, Soren se comprometió a desposarse con ella. Pero unas semanas antes del matrimonio rompió la relación. Kierkegaard siguió amando hasta el final de sus días a Regine, que nunca le perdonó el desaire. El suceso fue muy significativo para él y aludió al mismo repetidas veces en sus libros. La herencia recibida de su padre le permitió dedicarse por completo al pensamiento fílosófico. Kierkegaard señalaba que el hombre tiene que elegir entre el estadio de insensatez estética, en el que disfruta de los placeres de la existencia, y el estadio de lucidez ética. Sostenía que la filosofía sistemática no sólo impone una falsa perspectiva de la existencia humana, sino que también se convierte en una manera de evitar la responsabilidad. Creía que los individuos crean su propia naturaleza a través de su elección, que ha de hacerse sin el peso de normas universales y objetivas.

2- Hegel:Georg Wilhelm Friedrich Hegel (Stuttgart, 27 de agosto de 1770 - Berlín, 14 de noviembre de 1831), filósofo alemán nacido en Stuttgart, Wurtemberg, recibió su formación en el Tübinger Stift (seminario de la Iglesia Protestante en Wurtemberg), donde trabó amistad con el futuro filósofo Friedrich Schelling y el poeta Friedrich Hölderlin. Le fascinaron las obras de Platón, Aristóteles, Descartes, Spinoza, Kant, Rousseau, así como la Revolución Francesa, la cual acabó rechazando cuando esta cayó en manos del terror jacobino. Se le considera el último de los grandes metafísicos. Murió víctima de una epidemia de cólera, que hizo estragos durante el verano y el otoño de 1831.Considerado por la Historia Clásica de la Filosofía como el representante de la cumbre del movimiento decimonónico alemán del idealismo filosófico y como un revolucionario de la Dialéctica, habría de tener un impacto profundo en el materialismo histórico de Karl Marx. La relación intelectual entre Marx y Hegel ha sido una gran fuente de interés por la obra de Hegel.

3-Jean-Paul Charles Aymard Sartre (París, 21 de junio de 1905 - idem, 15 de abril de 1980), conocido comúnmente como Jean-Paul Sartre, fue un filósofo, escritor, novelista, dramaturgo, activista político, biógrafo y crítico literario francés, exponente del existencialismo y del marxismo humanista. Fue el décimo escritor francés seleccionado como Premio Nobel de Literatura, en 1964, pero lo rechazó explicando en una carta a la Academia Sueca que él tenía por regla declinar todo reconocimiento o distinción y que los lazos entre el hombre y la cultura debían desarrollarse directamente, sin pasar por las instituciones. Fue pareja de la también filósofa Simone de Beauvoir.La filosofía le atrajo desde su adolescencia en los años veinte, cuando leyó Essai sur les données immédiates de la conscience (Ensayo sobre los datos inmediatos de la consciencia) de Henri Bergson. Influenciado por Immanuel Kant, Georg Wilhelm Friedrich Hegel, Søren Kierkegaard, Edmund Husserl, y Martin Heidegger, entre otros. Sartre considera que el ser humano está "condenado a ser libre", es decir, arrojado a la acción y responsable plenamente de su vida, sin excusas. Aunque admite algunos 
condicionamientos (culturales, por ejemplo), no admite determinismos. Concibe la existencia humana como existencia consciente. El ser del hombre se distingue del ser de la cosa porque es consciente.

4-López, José García,Historia de la literatura española.8.ed.Vicens Vives,España,1997.p.720.Lázaro,Fernando y Tusón ,Vicente,Literatura Española, Coordinación Editorial ,España,1988,p.343,344.

5.htt;/WWW. es.wikipedia.org/wiki/Blas_de_Otero.

6-Lázaro,op.cit.p.344.

7- $h t t ; / W W W$. es.wikipedia.org/wiki/Blas_de_Otero.

8-Salvat,Manuel literarios de vanguardia,Salvat editores,Barcelona.1973.p.128 .

9- Lucas, Joaquin Benito ,Literatura de la posguerra.La poesía ,Editorial Cinel.S.A.1981.P.63.

10- Otero,Blas,Verso y Prosa,edición del autor,Catederaletras hispanicas,Ediciones Cátedra,S.A.,1996.P.47.

11-Friedrich Wilhelm Nietzsche (cerca de Lützen, 15 de octubre de 1844-Weimar, 25 de agosto de 1900)fueun filósofo, poeta, músico y filólogo alemán, considerado uno de los pensadores contemporáneos más influyentes del siglo XIX.

Realizó una crítica exhaustiva de la cultura, la religión y la filosofía occidental, mediante la genealogía de los conceptos que las integran, basada en el análisis de las actitudes morales (positivas y negativas) hacia la vida. ${ }^{1}$ Este trabajo afectó profundamente a generaciones posteriores de teólogos, antropólogos, filósofos, sociólogos, psicólogos, poetas, novelistas ydramat urgos. recibió amplio reconocimiento durante la segunda mitad del siglo XX como una figura significativa en la filosofía moderna. Su influencia fue particularmente notoria en los

filósofos existencialistas, críticos, fenomenológicos,postestructuralistas y postmodernos, y en la sociología de Max Weber.vease:

www.e s.wikipedia.org/wiki/Friedrich_Nietzsche .

12-Fiódor Mijáilovich Dostoyevski (ruso: Moscú, 11 de noviembre de 1821 -San Petersburgo, 9 de febrero de 1881) es uno de los principales escritores de la Rusia Zarista, cuya literatura explora la psicología humana en el complejo contexto político, social y espiritual de la sociedad rusa del siglo XIX. Es considerado como uno de los más grandes escritores de occidente y de la literatura universal. Walter Kaufmann citó las Memorias del subsuelo (1864), escritas con la amarga voz del anónimo «hombre subterráneo», como «la mejor obertura para el existencialismo jamás escrita». ${ }^{4}$ En el mismo sentido, el intelectual y escritor austríaco Stefan Zweigconsideró al escritor ruso «el mejor conocedor del alma humana de todos los tiempos».Su obra, aunque escrita en 
el siglo XIX, refleja también al hombre y la sociedad contemporánea.vease: www.e. s.wikipedia.org/wiki/Fiódor_Dostoyevski

13-Otero,Ancia,Prólogo de Damos Alonso,colección Visor de poesía,ed.12.Isaac Peral ,Madrid,1997.p.61

14-Jouaquin,op.cit.p.65.

15- Brown, Gerald G.Historia de la literatura Espanola.El siglo XX.Editorial s

16-Otero,op.cit.p. 25

17- Brown,op.cit.p.253.

18- Otero,Que trata de España,colección visor de poesía.ed.5.Graficas Valencia,1985.p.103

19- Rico, Francisco, Historia y critica de la literatura española ,Dario Villannueva y otros1975-18-90,Editorial Crítica ,Barcelona,1992.p.182.

20- Brown.op.cit.p.177.

21-Otero,Ancias.p.81

22-Lucas,op.cit.p.52

23-Otero.Ancias.p.74

24-Rico,op.cit.p.143

25-Otero,op.cit.p.140.

26- Canavaggio, Jean ,Historia de la literatura española,Tomo VI.El siglo XX.ed.1.Ariel.Barcelona,1995.p.255.

\section{V-Bibliografías:}

\section{Los Libros:}

Brown, Gerald G.Historia de la literatura Espanola.El siglo XX.

Editorial Ariel,S.A.Brcelona.ed.3.1985.

Canavaggio, Jean, Historia de la literature española,Tomo VI.El siglo XX.ed.1.Ariel.Barcelona,1995.

Jiménez, Felipe B.Pedraza - Cáceres, Milargos Rodriguez ,Manual de

literatura española :XI .Novecentismo y Vnguardia :líricos.

Cénlit ediciones.1993.

Javier del Prado,Teoría y Práctica de la fundión poética .Poesía siglo XX .Ediciones Cátedra .1993..

Lucas, Joaquin Benito ,Literatura de la posguerra.La poesía ,Editorial Cinel.S.A. 1981.

López, José García,Historia de la literatura española.8.ed.Vicens Vives,España, 
1997.

Otero,Blas ,Verso y Prosa,edicion del autor,Catederaletras hispanicas, Ediciones Cátedra,S.A.,1996.

Otero,Ancia,Prólogo de Damos Alonso,colección Visor de poesía,ed.12.Isaac Peral ,Madrid,1997.

Otero,Que trata de España,colección visor de poesía.ed.5.Graficas

Vlencia,1985.

Prata, Angel Valbuena ,Historia de la literatura española .8.ed.Editoria 1 Gustavo Gili.Brcelona.1969

Rico, Francisco „Historia y critica de la literatura española ,Dario Villannueva y otros1975-1990,Editorial Crítica ,Barcelona,1992.

Salvat,Manuel ,Movimientos literarios de vanguardia,Salvat editors,Barcelona.1973 .

Villanueva,Santos Sanz,Historia de la literature española,literatura actual.Arial,Barcelona, 1984.

\section{Sitios de Internet:}

htt;//WWW.https:lles.wikipedia .or/wiki/.jean-paul-Sartre.

htt;//WWW.es.wikipedia .or/iki/Soren-kierkegaard.

htt;//WWW.busabiografias.com/.../Soren Kierkegaard.

htt;//WWW.biografias y vidad.com/biografia/h/hegel.htm.

$h t t ; / / W W W$. es.wikipedia.org/wiki/Blas_de_Otero 


\section{ماهو أنساني وطبيعي في الوجودية لبلا س دي أوتيرو

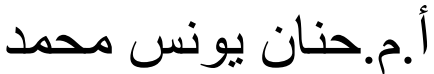 \\ جامعة بغداد /كلية الاداب /قشم اللغة الانكليزية

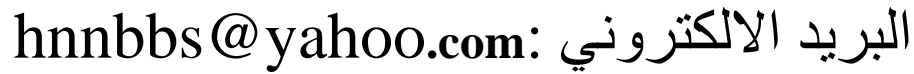

الخلاصة

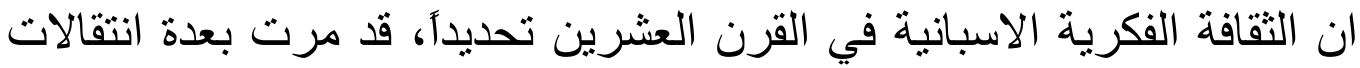

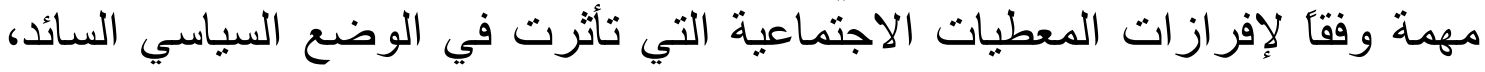

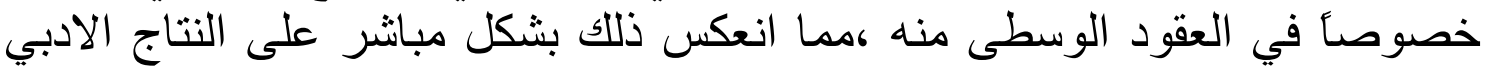

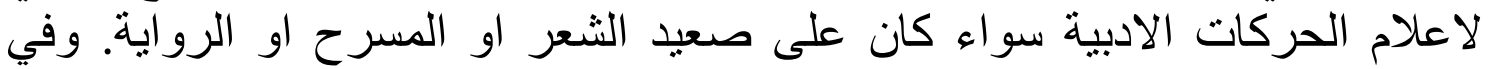

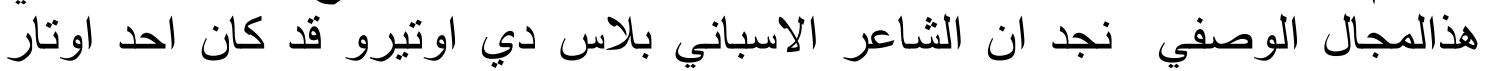

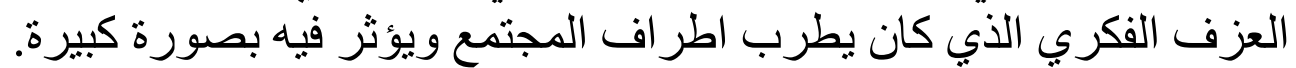

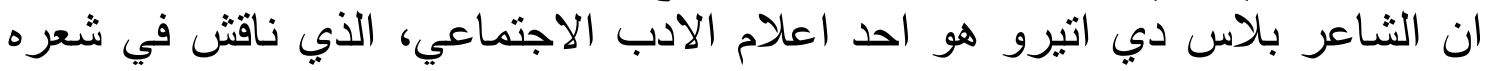

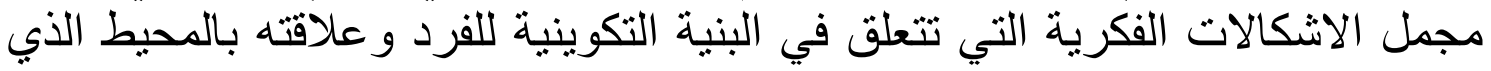

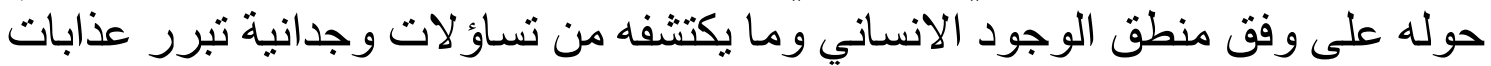

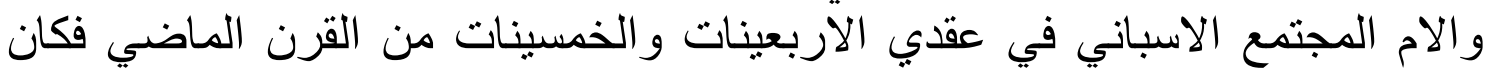

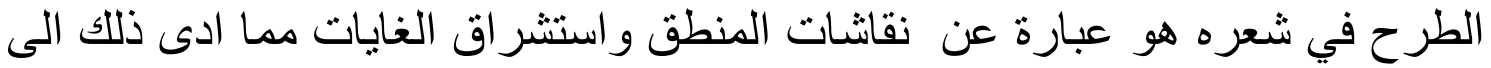

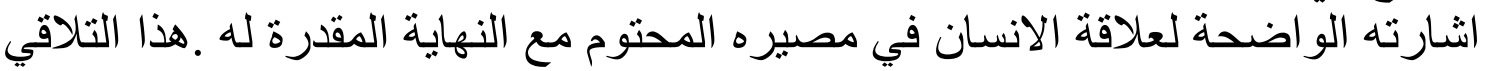

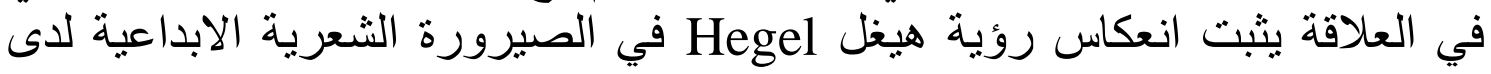

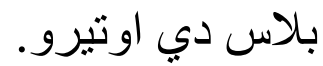

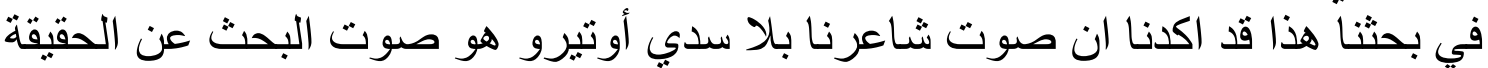

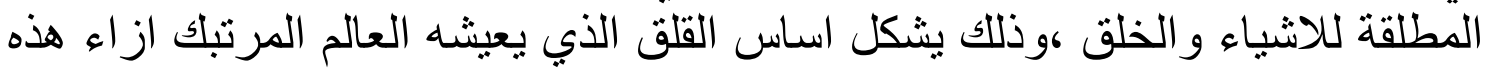

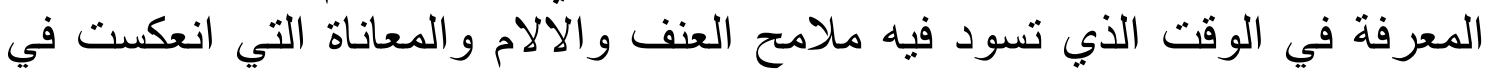

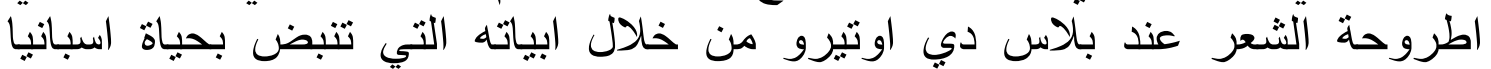
و الانسان الاسباني. 